\title{
Frecuencia de papilomatosis en bovinos (Bos taurus) del departamento de Córdoba, Colombia
}

\section{Frequency of papillomatosis in bovine (Bos taurus) of Córdoba Department, Colombia}

\author{
Violet L Lina ${ }^{1 *} M V Z$, Montes V Donicer ${ }^{2}$ Ph.D, Cardona A José1, Ph.D. \\ ${ }^{1}$ Universidad de Córdoba, Facultad de Medicina Veterinaria y Zootecnia, Departamento de Ciencias Pecuarias, \\ Grupo de Investigación en Medicina de Grandes Animales (MEGA), Montería, Colombia. \\ ${ }^{2}$ Universidad de Sucre. Facultad de Ciencias Agropecuarias, Departamento de Zootecnia. Sincelejo, Colombia
}

\section{Keywords:}

Skin disease;

tumor;

dermopathology.

\section{Abstract}

The objective of the present study was determining the frequency of cutaneous pailomatosis occurring in cattle (Bos taurus) in the Department of Córdoba. Of the dermathologyc cases treated in this period (1184), 117 (9.9\%) were clinical cases of cutaneous papillomatosis in cattle of different cattle farms of the Department. $42.7 \%(50 / 117)$ were males and $57.3 \%(67 / 117)$ were females. The most affected age group was 12 to 24 months with the highest number of cases (74/117 (63.2\%)), followed by those younger than 12 months $(22 / 117(18.8 \%))$ and the elderly Of 24 months $(21 / 117(17.9 \%))$. Regarding the location of lesions, the most common location in descending order was at the body level (69/117 (59.0\%)), Head (23/117 $(19.6 \%))$, extremities $(14 / 117(12.0 \%))$ and genitalia (11/117 (9.4\%)) respectively. No significant differences were observed in the frequency of papillomatosis ( $p>$ 0.05 ) with respect to age, sex, and location of lesions in study animals. It can be concluded that bovine cutaneous papillomatosis is one of the main causes of clinical consultation of care in cattle in the department of Córdoba.

\section{Resumen}

El objetivo del presente estudio fue determinar la frecuencia de pailomatosis cutánea que ocurren en bovinos (Bos taurus) en el Departamento de Córdoba. De los casos dermatológicos atendidos en ese periodo (1184), 117 (9,9\%) fueron casos clínicos de papilomatosis cutánea en bovinos de diferentes explotaciones ganaderas del Departamento. El 42,7\% (50/117) fueron machos y el 57,3\% (67/117) fueron hembras. El grupo etario más afectado fue el de 12 a 24 meses con mayor número de casos $(74 / 117(63,2 \%))$, seguido de los menores de 12 meses $(22 / 117$ $(18,8 \%))$ y los mayores de 24 meses $(21 / 117(17,9 \%))$. Con respecto a la ubicación de lesiones, la ubicación más común en orden descendente fue a nivel de cuerpo $(69 / 117(59,0 \%))$, Cabeza $(23 / 117(19,6 \%))$, extremidades $(14 / 117(12,0 \%))$ y genitales $(11 / 117(9,4 \%))$ respectivemente. No fueron observadas diferencias significativas en la frecuencia de papilomatosis $(p>0,05)$ con respecto a la edad, sexo y ubicación de las lesiones en los animales del estudio. Se puede concluir que la papilomatosis cutánea bovina es una de las principales causas de consulta clínica de atención en bovinos del departamento de Córdoba. 


\section{Introducción}

La papilomatosis cutánea bovina (PCB) es una enfermedad infectocontagiosa viral, crónica, caracterizada por la aparición de tumores benignos (fibropapilomas, papilomas o verrugas) en piel y mucosas (VIVAS et al., 2015), producida por diferentes tipos de Papilomavirus bovino (BPV); hasta el momento se han descrito 13 tipos de BPV (LUNARDI et al., 2016), los cuales presentan un genoma de ADN circular, doble cadena, y hacen parte de cuatro géneros de la familia Papillomaviridae, nombrados como: Deltapapillomavirus (BPV-1, BPV-2 y BPV-13), Xipapillomavirus (BPV-3, BPV-4, BPV-6, BPV-9, BPV-10, BPV-11, y BPV-12), Epsilonpapillomavirus (BPV-5 y BPV-8), y el recientemente clasificado Dyoxipapillomavirus (BPV-7); quienes presentan tropismo por células de diferentes órganos (LUNARDI et al., 2016); es así cómo los Deltapiapillomas se caracterizan por producir fibropapilomas cutáneos, los Xipapilomas por producir una lesión epitelial, y los Epsilonpapilomas producen fibropapilomas y papilomas epiteliales (CATROXO et al., 2013).

Resaltando la importancia de BPV-1 y 2, debido a que son los más frecuentes y con mayor distribución (LUNARDI et al., 2016), además de ocasionar lesiones en glándula mamaria y pene (CATROXO et al., 2013); el BPV-2 ha sido descrito afectando el tracto digestivo superior y vejiga, por lo que se le ha relacionado con el carcinoma de la vejiga urinaria que en conjunto con el helecho (Pteridium aquilinum) son los causantes de la hematuria enzoótica bovina (WOSIACKI et al., 2002; BARTH, 2016), también se ha descrito a los BPV-5, 9 y 10 en el desarrollo de fibropapilomas en la ubre, la presencia de BPV- 6 y 9 en las orejas (CATROXO et al., 2013), y el PBV-12 en el desarrollo de papilomas epiteliales cutáneos y de lengua (BARTH, 2016). De igual forma se tiene conocimiento de se pueden encontrar hasta cinco tipos diferentes de papilomavirus bovino en un mismo individuo (CLAUS et al., 2009; VÁSQUÉS et al., 2012).

La transmisión y propagación del virus se da a través de contacto directo con la piel, vectores mecánicos como garrapatas, y fómites, por lo que también se ven involucrados los bebederos, comederos, agujas y jeringas reutilizadas, e instalaciones contaminadas, a pesar de que se ha detectado su presencia en fluidos como sangre, leche, orina y semen (VÁSQUÉS et al., 2012), placenta y líquido amniótico (ROPERTO et al., 2012; CATROXO et al., 2013), el PVB es considerado cómo epiteliotrópico (VÁSQUÉS et al., 2012).

La PCB se describe con mayor frecuencia en animales jóvenes y hembras en lactancia, generalmente producen poco daño y desaparecen de forma espontánea, a menos que factores ambientales como las instalaciones inadecuadas, desnutrición y estrés inmuno comprometan al animal (VÁSQUÉS et al., 2012; CATROXO et al., 2013). Cuando los animales no son capaces de eliminar la infección, estas se disemina sobre el cuerpo de forma extensa, en la ubre dificultan el ordeño y amamantamiento, distorsionan los conductos galactóforos, y predisponen a consecuentes infecciones secundarias que producen mastitis y pueden extenderse a toda la zona ventral y periné, además de invasión por larvas de moscas (VÁSQUÉS et al., 2012), perdidas en la producción de leche y descarte prematuro de animales (CATROXO et al., 2013); Cuando los fibropapilomas se localizan en las pezuñas en el espacio interdigital, cojinetes y talones, son dolorosos y pueden provocar desde cojeras hasta postración (VÁSQUÉS et al., 2012). La piel es el principal órgano afectado, pues las lesiones y en ocasiones infecciones secundarias debilitan e imposibilitan su uso después del sacrificio, ocasionando pérdidas económicas (CATROXO et al., 2013).

El diagnóstico se basa en la caracterización de las lesiones, las cuales son pediculadas, de crecimiento exofítico y queratinizadas (CARDONA, 2016), Los papilomas crecen lentamente en forma de nódulos, luego aceleran su crecimiento y se van cornificando, por lo que pueden llegar a ser de diferentes formaS, pudiendo formar grandes masas de confluencia tumoral (VIVAS et al., 2015). Los papilomas más oscuros y bastante queratinizados se desprenden de la piel con mayor facilidad; los nódulos generalmente se ulceran siendo invadidos por infecciones secundarias (CATROXO et al., 2013; VIVAS et al., 2015).

A la histopatología se observa un crecimiento epitelial diferenciado con evidente hiperplasia, 
mostrando epidermis engrosada (acantosis) que emite proyecciones digitales hacía la dermis, e hiperqueratosis con tendencia al crecimiento y formación de túbulos de queratina; además de vacuolización nuclear en el estrato espinoso de la dermis (coilocitosis), con presencia de núcleos vacíos y otros cuerpos de inclusión (IGLESIAS Y BATISTA, 2003; VÁSQUÉS et al., 2012).

Se han planteado diversos tratamientos para la Papilomatosis bovina, tales como la extracción intervención quirúrgica, las vacunas autógenas preparadas con tejidos de verrugas del animal infectado, vacuna contra el virus de la enfermedad de Newcastle, diaceturato de diazoaminodibenzamidina, auto-hemoterapia, inyección de preparados que contienen bismuto y antimonio, tratamientos homeopáticos con Thuja ácido salicílico y látex de higuera; así mismo, los fármacos estimulantes del sistema inmune tales el levamisol y la ivermectina han sido utilizados exitosamente (VIVAS et al., 2015).

La finalidad del presente estudio fue determinar la frecuencia de presentación de papilomatosis cutánea en bovinos del Departamento de Córdoba, Colombia.

\section{Materiales y métodos}

Se realizó un estudio de tipo descriptivo retrospectivo en bovinos con pailomatosis cutánea (PCB) diagnosticados a través del examen clínico e histopatologico. Fue realizado en el departamento de Córdoba, Colombia, ubicado entre las coordenadas $7^{\circ} 23^{\prime}$ y $9^{\circ} 26^{\prime} \mathrm{LN}$ y los $74^{\circ} 52^{\prime}$ y $76^{\circ} 32^{\prime}$ LO del meridiano de Greenwich, a una altura de 30 m.s.n.m., con temperatura promedio anual de $28^{\circ} \mathrm{C}$, humedad relativa del $82 \%$, precipitación media anual de $1400 \mathrm{~mm}$ y pertenece a la formación climática de bosque tropical lluvioso (PABÓN et al., 2001).

De un total de 1184 casos dermatológicos atendidos en el periodo entre junio 2007 y junio de 2017, fueron utilizados 117 (9,9\%) casos clínicos de papilomatosis cutánea en bovinos de diferentes explotaciones ganaderas del Departamento, diagnosticados en el Servicio Clínico Ambulatorio de Grandes Animales de la Facultad de Medicina Veterinaria de la Universidad de Córdoba, los animales fueron de ambos sexos (67 hembras y 50 machos), con edades que oscilaron entre 5 y 36 meses y clasificados en tres grupos etarios (< 12 meses, de 12 a 24 meses y $>24$ meses).

Para la evaluación de los animales y la toma de muestras, se tuvieron en cuenta las normas técnicas referentes a los principios éticos internacionales para la investigación biomédica con animales del CIOMS (Council for International Organizations of Medical Sciences) establecida por la UNESCO (UnitedNationsEducational, Scientific and Cultural Organization) y la OMS (Organización Mundial de la Salud) de 1949 y de la Ley 84 de Octubre 27 de 1989 (Estatuto Colombiano de Protección Animal) (MRAD, 2006).

Los diagnósticos fueron realizados mediante examen clínico general y dermatológico especial (inspección directa, inspección con lupa y palpación), histopatología, prueba de $\mathrm{KOH}$ y respuesta terapéutica. A todas las lesiones cutáneas se les realizó caracterización anatomopatológica, siendo tomadas fotografías de alta definición para su posterior análisis (Sony DSC-HX10V, China). Se realizaron raspados cutáneos que fueron procesados con la prueba de $\mathrm{KOH}$ en el laboratorio Clínico Veterinario, de igual forma se colectaron biopsias de tejido de lesiones granulomatosas (CARDONA et al., 2013), para ser fijadas en formalina al $10 \%$, procesadas hasta su inclusión en parafina, cortadas a $5 \mu \mathrm{m}$ de espesor en un micrótomo (Leica RM2125 RTS $®$, Japón) y coloreadas con Hematoxilina - Eosina (HE) en el laboratorio de Patología Animal del Departamento de Ciencias Pecuarias de la Universidad de Córdoba, Colombia.

Se utilizó la prueba de Chi-cuadrado con el fin de determinar diferencias $(p \leq 0,05)$ entre las variables (diagnóstico, sexo y edad). La tabulación, organización y el análisis estadístico de los datos fue realizado con el auxilio del programa de computador S.A.S. 9.1.3.

\section{Resultados y discusión}

Las manifestaciones clínicas observadas en los animales con PCB, las características anatomopatológicas de las lesiones, los resultados de los raspados cutáneos e histopatológicos confirmaron el diagnóstico de PCB en los 117 
bovinos estudiados, de acuerdo con lo reportado como método de diagnóstico de la papilomatosis cutánea en bovinos (VÁSQUÉS et al., 2012; CATROXO et al., 2013; VIVAS et al., 2015; CARDONA, 2016), con una frecuencia de presentación del 9,9\% en diferentes explotaciones ganaderas del departamento de Córdoba, Colombia.

En la Tabla 1 se describe la distribución de la papilomatosis cutánea en los bovinos estudiados según el sexo, edad y ubicación de las lesiones, en la cual el $42,7 \%$ (50/117) fueron machos y el $57,3 \%$ (67/117) fueron hembras. El grupo etario más afectado fue el de 12 a 24 meses con el $63,2 \%$ (74/117), seguido de los menores de 12 meses con $18,8 \%(22 / 117)$ y los mayores de 24 meses con 17,9\% (21/117) respectivamente. La ubicación de lesiones más común en orden descendente fue a nivel de cuerpo (69/117 $(59,0 \%))$ (Figura 1a), Cabeza $(23 / 117(19,6 \%))$ (Figura 1b), extremidades $(14 / 117(12,0 \%))$ (Figura 1c) y genitales $(11 / 117(9,4 \%))$ (Figura 1d) respectivemente. No fueron observadas diferencias significativas en la frecuencia de papilomatosis $(p>0,05)$ con respecto a la edad, sexo y ubicación de las lesiones en los animales del estudio.

En todas las biopsias de tejido tumoriforme coloreadas con $\mathrm{HE}$, se observaron características histopatológicas similares caracterizadas por hiperplasia epitelial con proyecciones hacía la dermis e hiperqueratosis que permitieron ratificar el diagnóstico clínico de acuerdo con lo reportado como método diagnóstico de la papilomatosis bovina (VÁSQUÉS et al., 2012).
La frecuencia de presentación de papilomatosis cutánea en bovinos fue del $9,9 \%$, pudiendo deberse a las condiciones agroecológicas de bosque tropical lluvioso, con temperatura promedio de $28^{\circ} \mathrm{C}$ y humedad relativa del $82 \%$, lo que favorece las condiciones propicias para la presentación de enfermedades infecciosas (producción de vectores o replicación de microorganismos) (CARDONA et al., 2013), lo que concuerda con lo reportado por CARDONA et al. (2017) y BUITRAGO et al. (2017), quienes informaron a la papilomatosis como la cuarta enfermedad dermatológica más frecuente en bovinos del departamento de Córdoba. De igual forma, REIS et al. (2017) informan al papiloma como la segunda causa neoplásica después del carcinoma en rumiantes de Porto Alegre (Brasil), mientras que CARVALHO et al. (2014), la reportaron como la 3 causa neoplásica en rumiantes del Nordeste Brasilero después del melanoma y del carcinoma de células escamosas; por lo que CATROXO et al. (2013), encontraron una prevalencia de papilomatosis bovina del $20 \%$ en Yucatán, México. SCHUCH (2007), manifiesta que al ser los papilomas de fácil transmisión, son muy frecuentemente encontrados en la práctica clínica de campo, ya que por su apariencia macroscópica es muy bien conocida por los Médicos Veterinarios, siendo informado en forma de brotes en las explotaciones ganaderas donde son diagnósticados.

Las lesiones se ubicaron con mayor presencia a nivel corporal seguido de la cabeza, concordado con los informado por GARCÍA (2017), quien encontró mayor presencia de lesiones a nivel de torax, seguido de la cabeza. CARVALHO et al. (2012), manifiestan que existe una marcada presencia de co-infecciones encontrando mas del

Tabla 1. Distribución de las lesiones según sexo, edad y ubicación de las lesiones en 117 bovinos estudiados en Córdoba, Colombia.

\begin{tabular}{|c|c|c|c|c|c|c|c|}
\hline \multirow{2}{*}{$\begin{array}{l}\text { Ubicación de } \\
\text { las lesiones }\end{array}$} & \multicolumn{3}{|c|}{ Hembras $n^{\circ}(\%) 67(57,3)$} & \multicolumn{3}{|c|}{ Machos $n^{\circ}(\%) 50(42,7 \%)$} & \multirow{2}{*}{ Total $n^{\circ}(\%)$} \\
\hline & $\begin{array}{c}<12 \\
\text { Meses }\end{array}$ & $\begin{array}{l}12 \text { a } 24 \\
\text { Meses }\end{array}$ & $\begin{array}{c}>24 \\
\text { Meses }\end{array}$ & $\begin{array}{c}<12 \\
\text { Meses }\end{array}$ & $\begin{array}{l}12 \text { a } 24 \\
\text { Meses }\end{array}$ & $\begin{array}{c}>24 \\
\text { Meses }\end{array}$ & \\
\hline Cabeza & 2 & 8 & 2 & 3 & 7 & 1 & $23(19,6)$ \\
\hline Cuerpo & 9 & 26 & 2 & 6 & 23 & 3 & $69(59,0)$ \\
\hline Extremidades & 1 & 2 & 5 & 1 & 1 & 4 & $14(12,0)$ \\
\hline Genitales & - & 3 & 2 & - & 4 & 2 & $11(9,4)$ \\
\hline TOTAL $\mathrm{n}^{\circ}(\%)$ & $12(10,3)$ & $39(33,3)$ & $11(9,4)$ & $10(8,5)$ & $35(29,9)$ & $10(8,5)$ & $117(100)$ \\
\hline
\end{tabular}




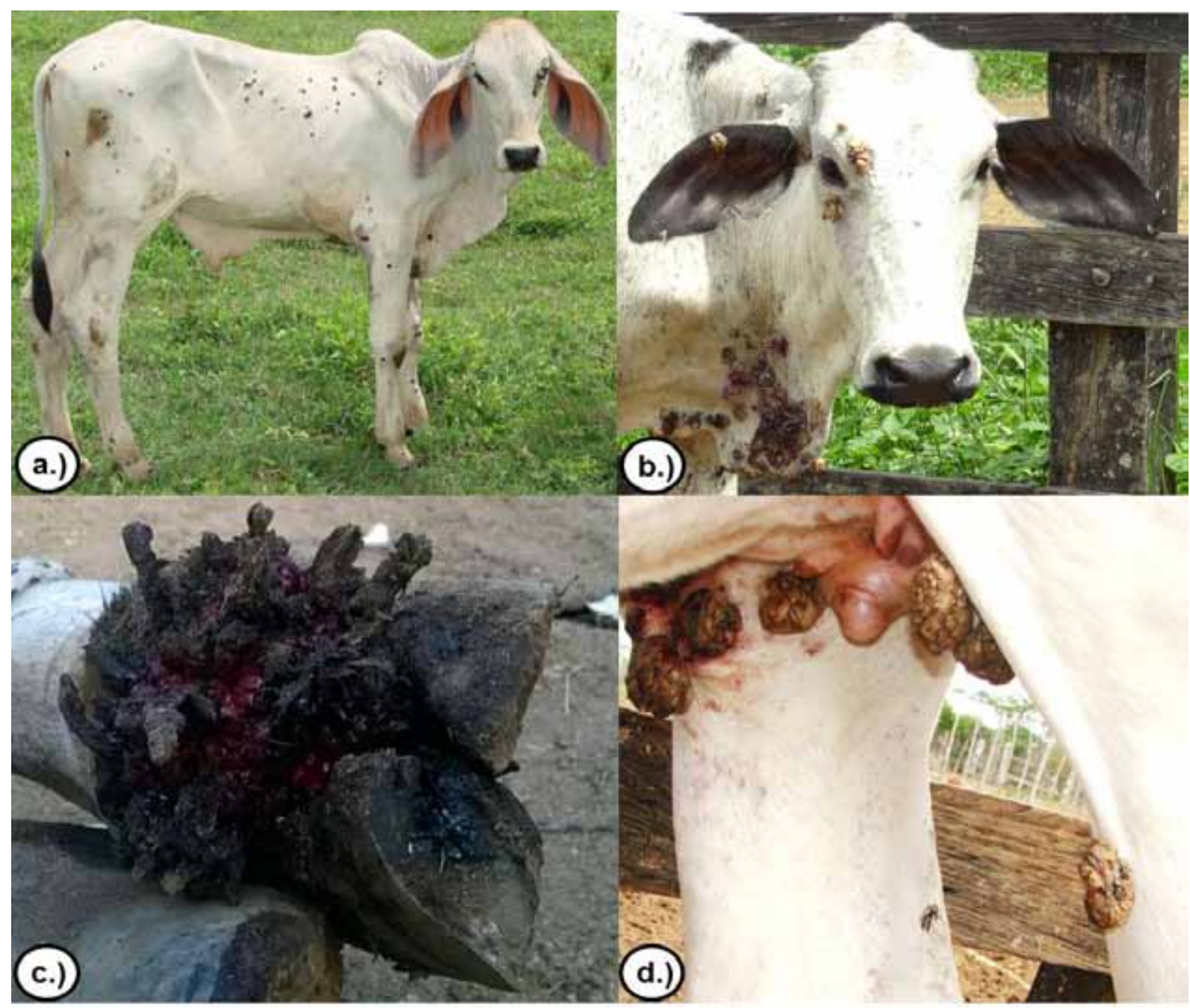

Figura 1. Ubicación de las lesiones papilomatosas en los animales estudiados. a.) a nivel de cuerpo. b.) cabeza y cuello. c.) extremidades. d.) genitales.

$80 \%$ de las muestras analizadas de papilomas cutáneos en vacas en Brasil con infecciones de al menos 2 o 3 genotipos.

La mayor presentación de PCB, se dio en animales jóvenes menores de 24 meses, coincidiendo con lo reportado por VÁSQUÉS et al. (2012) y CATROXO et al. (2013), quienes informaron mayor frecuencia en animales jóvenes y hembras en lactancia.
La papilomatosis cutánea bovina puede ocasionar pérdidas económicas en la industria del ganado, debido a la disminución en rendimiento, ya sea por alteraciones estéticas, costos elevados de tratamientos, muertes o descartes, ratificando la necesidad del conocimiento clínico-epidemiológico de la papilomatosis bovina y de esta manera establecer planes profilácticos o de manejo y control. 


\section{Referencias}

BARTH D. Detecção de papilomavirus e caracterização genotipica em bovinos leiteiros. Tesis de Mestrado em Saúde e Produção em Ruminantes, - Universidade Norte do Paraná, Arapongas, Brasil. 2016. [Acceso: 23/07/2017]. Disponible en URL: http://repositorio.pgsskroton.com.br/bitstream/123456789/861/1/ Detec\%C3\%A7\%C3\%A3o\%20de\%20papilomavirus\%20e\%20caracteriza\%C3\%A7\%C3\%A30\%20 genotipica\%20em\%20bovinos\%20leiteiros.pdf

BUITRAGO-MEJIA J; DIAZ-CUETO M; SUAREZ-CHICA A; CARDONA-ALVAREZ J. Distribucion geografica de la casuistica clinica bovina del servicio ambulatorio de grandes animales de la Universidad de Cordoba (Colombia). Rev. Med. Vet. 2017; 34 (Supl):101-113.

CARDONA J. Conceptos Generales sobre Dermatología Tropical en Grandes Animales. Memorias del I Seminario Internacional de reproducción y clínica en bovinos, ovinos y equinos. Auditorio de postgrados de la Policía nacional. Bogotá, 4 y 5 de noviembre de 2016.

CARDONA J; MARTÍNEZ M; MAZA L. Casuística clínica más frecuente en el servicio ambulatorio de grandes animales de la Universidad de Córdoba, Colombia. Rev Colombiana Cienc Anim. 2017; 9(1): 66-72.

CARDONA J; VARGAS M; GONZALEZ M. Evaluación clínica e histopatológica de la Pythiosis cutánea en terneros del departamento de Córdoba, Colombia. Rev MVZ Cordoba. 2013; 18(2): 3551-3558.

CARVALHO F; DANTAS A; RIET-CORREA F; ANDRADE R; NÓBREGA P; MIRANDA E; SIMÕES S; AZEVEDO S. Estudo retrospectivo das neoplasias em ruminantes e equídeos no semiárido do Nordeste Brasileiro. Pesquisa Veterinária Brasileira. 2014; 34(3): 211-216.

CARVALHO F; DANTAS A; RIET-CORREA F; MIRANDA-NETO E; SIMÕES S; AZEVEDO S. Fatores de risco associados à ocorrência de carcinoma de células escamosas em ruminantes e equinos no semiárido da Paraíba. Pesq. Vet. Bras. 2012; 32(9): 881-886.

CATROXO M; MARTINS A; PETRELLA S; SOUZA F; NASTARI B. Ultrastructural Study of Bovine Papillomavirus During Outbreaks in Brazil. International Journal of Morphology. 2013; 31(2): 777-784

CLAUS M; LUNARDI M; ALFIERI A; OTONEL R; SARTORI D; FUNGARO M. Multiple bovine papillomavirus infections associated with cutaneous papillomatosis in Brazilian cattle herds. Brazilian Archives of Biology and Technology. 2009; 52(Supl): 93-98.

GARCÍA-DÍAZ J. Efecto de la suplementación parenteral de cobre Zinc y Manganeso en el tratamiento de la papilomatosis cutánea bovina. REDVET. 2017; 18 (1): 1-10

IGLESIAS A; BATISTA L. Caracterização anatomopatológica da papilomatose cutânea em bovinos leiteiros. Rev. Bras. Ciênc. Vet. 2003;10(3): 161-165.

LUNARDI M; DE CAMARGO C; ALFIERI A; DE ALCÂNTARA B; VILAS L; OTONEL R. Genetic diversity of bovine papillomavirus types, including two putative new types, in teat warts from dairy cattle herds. Arch. Virology. 2016; 161(6): 1569-1577.

MRAD, A. Ética en la investigación con modelos animales experimentales. Alternativas y las 3 RS de Russel. Una responsabilidad y un compromiso ético que nos compete a todos. Rev. Col. Bioética. 2006; 1(1): 163-184. 
PABÓN, J.; ESLAVA, J.; GÓMEZ, R. Generalidades de la distribución espacial y temporal de la temperatura del aire y de la precipitación en Colombia. Meteorol. Colomb. 2001; 4: 47-59.

REIS M; SLAVIERO M; LORENZETT M; CRUZ R; GUIMARÃES L; PAVARINI S; DRIEMEIER D; SONNE L. Neoplasmas bovinos diagnosticados no Setor de Patologia Veterinária da UFRGS, Porto Alegre (20052014). Pesquisa Veterinária Brasileira. 2017; 37(2): 105-109.

ROPERTO S; BORZACCHIELLO G; ESPOSITO I; RICCARDI M; URRARO C; LUCÀ R. Productive infection of bovine papillomavirus type 2 in the placenta of pregnant cows affected with urinary bladder tumors. PLoS One. 2012; 7(3): e33569.

SCHUCH L. 2007. Papilomatose bovina, p.179-182. In: Riet-Correa F., Schild A.L., Lemos R.A.A. \& Borges J.R.J. (Eds), Doenças de Ruminantes e Equídeos. Vol.1. Pallotti, Santa Maria, Brasil.

VÁSQUÉS R; ESCUDERO C; DOMÉNECH A; GÓMEZ E; BENÍTEZ L. Papilomatosis bovina: epidemiología y diversidad de papilomavirus bovinos (BPV). Rev. Complut. Cienc. Vet. 2012; 6(2): 38-57.

VIVAS R; CORDERO L; RUIZ E; CÁRDENAS M; MELINA M; NAVARRO R. Papilomatosis bovina en el trópico mexicano: presentación clínica y control. Bioagrociencias. 2015; 8(1): 45-52.

WOSIACKI R; REIS A; ALFIERI A; ALFIERI A. Papilomavírus bovino tipo 2 na etiologia da hematúria enzoótica bovina. Semina: Ciências Agrárias, Londrina. 2002; 23(1): 121-130. 